\title{
Coupled common fixed point theorems for a pair of commuting mappings in partially ordered G-metric spaces
}

Feng $\mathrm{Gu}^{*}$ and Shuhang Zhou

\section{"Correspondence: \\ gufeng99@sohu.com \\ Department of Mathematics, \\ Institute of Applied Mathematics, \\ Hangzhou Normal University, \\ Hangzhou, Zhejiang 310036, China}

\begin{abstract}
In this paper, we introduce a new contractive condition for a pair of commuting mappings in partially ordered G-metric spaces. Some new coupled coincidence point and coupled common fixed point theorems are obtained. An example is given to support the usability of our results. The results presented in this paper generalize and improve the corresponding results of Nashine and Shatanawi from partially ordered metric spaces to partially ordered $\mathrm{G}$-metric spaces.
\end{abstract}

MSC: 47H10; 54H25; 54E50

Keywords: $G$-metric space; mixed g-monotone property; coupled coincidence point; coupled common fixed point; partial order

\section{Introduction and preliminaries}

In 2004, Ran and Reurings [1] showed the existence of fixed points of nonlinear contraction mappings in metric spaces endowed with a partial ordering and presented applications of their results to matrix equations. Subsequently, Nieto and Rodríguez-López [2, 3] extended the corresponding results in [1]. They proved the existence theorems of a unique fixed point for mappings in partially ordered sets and gave some applications to the existence of a unique solution for a first-order ordinary differential equation with periodic boundary conditions.

In 2005, the well-known Tarski theorem [4] was used in [5] to study the existence of solutions for fuzzy equations and to prove existence theorems for fuzzy differential equations.

It is well known that fixed point theory in partially ordered metric spaces as one of the most important tools of nonlinear analysis has been widely applied to matrix equations (for more details, see [1] and the references therein), ordinary differential equations (for more details, see $[2,3,6]$ and [7] and the references therein), fuzzy differential equations (for more details, see [5] and the references therein), integral equations (for more details, see [8] and [9] and the references therein) and intermediate value theorems (for more details, see [10] and the references therein). For more results on partially ordered metric spaces, one refers to the results in [11-21].

In 2006, Bhaskar and Lakshmikantham [22] introduced the notion of a coupled fixed point and proved some interesting coupled fixed point theorems for the mappings satisfying a mixed monotone property; while Lakshmikantham and Ćirić [23] introduced the 
concept of a mixed $g$-monotone mapping and proved coupled coincidence and coupled common fixed point theorems that extended the theorems due to Bhaskar and Lakshmikantham [22]. Subsequently, many authors obtained many coupled coincidence and coupled fixed point theorems in ordered metric spaces; see [24-29] and the references therein.

In 2006, Mustafa and Sims [30] introduced the notion of generalized metric spaces or simply $G$-metric spaces as a generalization of the concept of a metric space. Based on the concept of a G-metric space, many authors obtained many fixed point and common fixed point theorems for the mappings satisfying different contractive conditions; see [3142] for more details. Fixed point problems also have been considered in partially ordered G-metric spaces; see [43-55] and the references therein for more details.

Inspired and motivated by the facts said above, in this paper we establish coupled coincidence point and coupled common fixed point theorems for a pair of commuting mappings in partially ordered G-metric spaces. An example is given to support the usability of our results. The results presented in this paper generalize and improve the corresponding results of Nashine and Shatanawi [29] from partially ordered metric spaces to partially ordered G-metric spaces.

First, we present some known definitions and propositions.

Definition 1.1 [30] Let $X$ be a nonempty set, and let $G: X \times X \times X \rightarrow R^{+}$be a function satisfying the following axioms:

(G1) $G(x, y, z)=0$ if $x=y=z$;

(G2) $0<G(x, x, y)$ for all $x, y \in X$ with $x \neq y$;

(G3) $G(x, x, y) \leq G(x, y, z)$ for all $x, y, z \in X$ with $z \neq y$;

(G4) $G(x, y, z)=G(x, z, y)=G(y, z, x)=\cdots$ (symmetry in all three variables);

(G5) $G(x, y, z) \leq G(x, a, a)+G(a, y, z)$ for all $x, y, z, a \in X$ (rectangle inequality).

Then the function $G$ is called a generalized metric or, more specifically, a $G$-metric on $X$ and the pair $(X, G)$ is called a $G$-metric space.

It is known that the function $G(x, y, z)$ on a $G$-metric space $X$ is jointly continuous in all three of its variables, and $G(x, y, z)=0$ if and only if $x=y=z$; see [30] and the references therein for more details.

Definition 1.2 [30] Let $(X, G)$ be a $G$-metric space, and let $\left\{x_{n}\right\}$ be a sequence of points in $X$. A point $x$ in $X$ is said to be the limit of the sequence $\left\{x_{n}\right\}$ if $\lim _{m, n \rightarrow \infty} G\left(x, x_{n}, x_{m}\right)=0$, and one says that the sequence $\left\{x_{n}\right\}$ is $G$-convergent to $x$.

Thus, if $x_{n} \rightarrow x$ in a $G$-metric space $(X, G)$, then for any $\epsilon>0$, there exists $N \in \mathbb{N}$ such that $G\left(x, x_{n}, x_{m}\right)<\epsilon$ for all $n, m \geq N$.

Proposition 1.1 [30] Let $(X, G)$ be a G-metric space. Then the following are equivalent:

(1) $\left\{x_{n}\right\}$ is G-convergent to $x$;

(2) $G\left(x_{n}, x_{n}, x\right) \rightarrow 0$ as $n \rightarrow \infty$;

(3) $G\left(x_{n}, x, x\right) \rightarrow 0$ as $n \rightarrow \infty$;

(4) $G\left(x_{n}, x_{m}, x\right) \rightarrow 0$ as $n, m \rightarrow \infty$. 
Definition 1.3 [30] Let $(X, G)$ be a $G$-metric space. A sequence $\left\{x_{n}\right\}$ is called a $G$-Cauchy sequence if, for each $\epsilon>0$, there exists a positive integer $N \in \mathbb{N}$ such that $G\left(x_{n}, x_{m}, x_{l}\right)<\epsilon$ for all $n, m, l \geq N$; that is, $G\left(x_{n}, x_{m}, x_{l}\right) \rightarrow 0$ as $n, m, l \rightarrow \infty$.

Definition 1.4 [30] A G-metric space $(X, G)$ is said to be $G$-complete if every $G$-Cauchy sequence in $(X, G)$ is $G$-convergent in $X$.

Proposition 1.2 [30] Let $(X, G)$ be a G-metric space. Then the following are equivalent:

(1) The sequence $\left\{x_{n}\right\}$ is G-Cauchy;

(2) For every $\epsilon>0$, there exists $k \in \mathbb{N}$ such that $G\left(x_{n}, x_{m}, x_{m}\right)<\epsilon$ for all $n, m \geq k$.

Definition 1.5 [30] Let $(X, G)$ and $\left(X^{\prime}, G^{\prime}\right)$ be two G-metric spaces. Then $f: X \rightarrow X^{\prime}$ is $G$-continuous at $x \in X$ if and only if it is $G$-sequentially continuous at $x$; that is, whenever $\left\{x_{n}\right\}$ is $G$-convergent to $x,\left\{f\left(x_{n}\right)\right\}$ is $G$-convergent to $f(x)$.

Proposition 1.3 [30] Let $(X, G)$ be a G-metric space. Then, for any $x, y \in X$, we have $G(x, y, y) \leq 2 G(y, x, x)$.

Definition 1.6 [43] Let $(X, G)$ be a $G$-metric space. A mapping $F: X \times X \rightarrow X$ is said to be continuous if for any two G-convergent sequences $\left\{x_{n}\right\}$ and $\left\{y_{n}\right\}$ converging to $x$ and $y$ respectively, $\left\{F\left(x_{n}, y_{n}\right)\right\}$ is $G$-convergent to $F(x, y)$.

Definition 1.7 [22] An element $(x, y) \in X \times X$ is called a coupled fixed point of the mapping $F: X \times X \rightarrow X$ if $F(x, y)=x$ and $F(y, x)=y$.

Definition 1.8 [23] An element $(x, y) \in X \times X$ is called a coupled coincidence point of the mappings $F: X \times X \rightarrow X$ and $g: X \rightarrow X$ if $F(x, y)=g x$ and $F(y, x)=g y$.

Definition 1.9 [23] Let $X$ be a nonempty set. Then we say that the mappings $F: X \times X \rightarrow$ $X$ and $g: X \rightarrow X$ are commutative if $g F(x, y)=F(g x, g y)$.

Definition 1.10 [22] Let $(X, \preceq)$ be a partially ordered set and $F: X \times X \rightarrow X$. The mapping $F$ is said to have the mixed monotone property if $F(x, y)$ is monotone non-decreasing in $x$ and is monotone non-increasing in $y$; that is, for any $x, y \in X$, we have

$$
x_{1}, x_{2} \in X, \quad x_{1} \preceq x_{2} \quad \Rightarrow \quad F\left(x_{1}, y\right) \preceq F\left(x_{2}, y\right)
$$

and

$$
y_{1}, y_{2} \in X, \quad y_{1} \preceq y_{2} \quad \Rightarrow \quad F\left(x, y_{1}\right) \succeq F\left(x, y_{2}\right) .
$$

Definition 1.11 [23] Let $(X, \preceq)$ be a partially ordered set and $F: X \times X \rightarrow X$ and $g$ : $X \rightarrow X$. The mapping $F$ is said to have the mixed $g$-monotone property if $F$ is monotone $g$-nondecreasing in its first argument and is monotone $g$-nonincreasing in its second argument; that is, for any $x, y \in X$, we have

$$
x_{1}, x_{2} \in X, \quad g\left(x_{1}\right) \preceq g\left(x_{2}\right) \quad \Rightarrow \quad F\left(x_{1}, y\right) \preceq F\left(x_{2}, y\right)
$$


and

$y_{1}, y_{2} \in X, \quad g\left(y_{1}\right) \preceq g\left(y_{2}\right) \quad \Rightarrow \quad F\left(x, y_{1}\right) \succeq F\left(x, y_{2}\right)$.

\section{Main results}

Theorem 2.1 Let $(X, \preceq)$ be a partially ordered set and $(X, G)$ be a G-metric space. Let $F: X \times X \rightarrow X$ and $g: X \rightarrow X$ be mappings such that $F$ has the mixed $g$-monotone property on $X$. Suppose there exist non-negative real numbers $\alpha, \beta, \gamma$ and $L$ with $\beta+\gamma<1$ such that

$$
\begin{aligned}
& G(F(x, y), F(u, v), F(w, z)) \\
& \leq \alpha \min \{G(F(x, y), g x, g x), G(F(u, v), g x, g x), G(F(w, z), g x, g x)\} \\
&+\beta \min \{G(F(x, y), g u, g u), G(F(u, v), g u, g u), G(F(w, z), g u, g u)\} \\
&+\gamma \min \{G(F(x, y), g w, g w), G(F(u, v), g w, g w), G(F(w, z), g w, g w)\} \\
&+L \min \{G(F(x, y), g u, g u), G(F(u, v), g w, g w), G(F(w, z), g x, g x)\}
\end{aligned}
$$

for all $(x, y),(u, v),(w, z) \in X \times X$ with $g(x) \preceq g(u) \preceq g(w)$ and $g(y) \succeq g(v) \succeq g(z)$. Further suppose $F(X \times X) \subset g(X)$ and $g(X)$ is a complete subspace of $X$. Also suppose that $X$ satisfies the following properties:

(i) if a non-decreasing sequence $\left\{x_{n}\right\}$ in $X$ converges to $x \in X$, then $x_{n} \preceq x$ for all $n \in \mathbb{N}$;

(ii) if a non-increasing sequence $\left\{y_{n}\right\}$ in $X$ converges to $y \in X$, then $y_{n} \succeq y$ for all $n \in \mathbb{N}$.

If there exist two elements $x_{0}, y_{0} \in X$ such that $g\left(x_{0}\right) \preceq F\left(x_{0}, y_{0}\right)$ and $g\left(y_{0}\right) \succeq F\left(y_{0}, x_{0}\right)$, then $F$ and $g$ have a coupled coincidence point. That is, there exists $(x, y) \in X \times X$ such that $F(x, y)=g(x)$ and $F(y, x)=g(y)$.

Proof In view of the condition of the theorem, we see that there exist $x_{0}, y_{0} \in X$ such that $g\left(x_{0}\right) \preceq F\left(x_{0}, y_{0}\right)$ and $g\left(y_{0}\right) \succeq F\left(y_{0}, x_{0}\right)$. Since $F(X \times X) \subset g(X)$, we can choose $x_{1}, y_{1} \in X$ such that $g\left(x_{1}\right)=F\left(x_{0}, y_{0}\right)$ and $g\left(y_{1}\right)=F\left(y_{0}, x_{0}\right)$. Again since $F(X \times X) \subset g(X)$, we can choose $x_{2}, y_{2} \in X$ such that $g\left(x_{2}\right)=F\left(x_{1}, y_{1}\right)$ and $g\left(y_{2}\right)=F\left(y_{1}, x_{1}\right)$. Continuing in this way, we construct two sequences $\left\{x_{n}\right\}$ and $\left\{y_{n}\right\}$ in $X$ such that

$$
g\left(x_{n+1}\right)=F\left(x_{n}, y_{n}\right) \quad \text { and } \quad g\left(y_{n+1}\right)=F\left(y_{n}, x_{n}\right), \quad \forall n \geq 0 .
$$

Now we prove that

$$
g\left(x_{n}\right) \preceq g\left(x_{n+1}\right) \quad \text { and } \quad g\left(y_{n}\right) \succeq g\left(y_{n+1}\right), \quad \forall n \geq 0 .
$$

We will use the mathematical induction. Let $n=0$. Since $g\left(x_{0}\right) \preceq F\left(x_{0}, y_{0}\right)$ and $g\left(y_{0}\right) \succeq$ $F\left(y_{0}, x_{0}\right)$, in view of $g\left(x_{1}\right)=F\left(x_{0}, y_{0}\right)$ and $g\left(y_{1}\right)=F\left(y_{0}, x_{0}\right)$, we have $g\left(x_{0}\right) \preceq g\left(x_{1}\right)$ and $g\left(y_{0}\right) \succeq$ $g\left(y_{1}\right)$; that is, (2.3) hold for $n=0$. We assume that (2.3) hold for some $n>0$. As $F$ has the mixed $g$-monotone property, $g\left(x_{n}\right) \preceq g\left(x_{n+1}\right)$ and $g\left(y_{n}\right) \succeq g\left(y_{n+1}\right)$, from (2.2) we get that

$$
g\left(x_{n+1}\right)=F\left(x_{n}, y_{n}\right) \preceq F\left(x_{n+1}, y_{n}\right) \quad \text { and } \quad g\left(y_{n+1}\right)=F\left(y_{n}, x_{n}\right) \succeq F\left(y_{n+1}, x_{n}\right) .
$$

In the same way, we obtain that

$$
g\left(x_{n+2}\right)=F\left(x_{n+1}, y_{n+1}\right) \succeq F\left(x_{n+1}, y_{n}\right) \quad \text { and } \quad g\left(y_{n+2}\right)=F\left(y_{n+1}, x_{n+1}\right) \preceq F\left(y_{n+1}, x_{n}\right) .
$$


By combining (2.4) and (2.5), we obtain $g\left(x_{n+1}\right) \preceq g\left(x_{n+2}\right)$ and $g\left(y_{n+1}\right) \succeq g\left(y_{n+2}\right)$. Thus, by the mathematical induction, we conclude that (2.3) hold for all $n \geq 0$.

We check easily that

$$
g\left(x_{0}\right) \preceq g\left(x_{1}\right) \preceq g\left(x_{2}\right) \preceq \cdots \preceq g\left(x_{n}\right) \preceq g\left(x_{n+1}\right) \preceq \cdots
$$

and

$$
g\left(y_{0}\right) \succeq g\left(y_{1}\right) \succeq g\left(y_{2}\right) \succeq \cdots \succeq g\left(y_{n}\right) \succeq g\left(y_{n+1}\right) \succeq \cdots .
$$

It follows from (2.1) and (2.2) that

$$
\begin{aligned}
& G\left(g x_{n+1}, g x_{n}, g x_{n}\right) \\
&=G\left(F\left(x_{n}, y_{n}\right), F\left(x_{n-1}, y_{n-1}\right), F\left(x_{n-1}, y_{n-1}\right)\right) \\
& \leq \alpha \min \left\{G\left(F\left(x_{n}, y_{n}\right), g x_{n}, g x_{n}\right), G\left(F\left(x_{n-1}, y_{n-1}\right), g x_{n}, g x_{n}\right), G\left(F\left(x_{n-1}, y_{n-1}\right), g x_{n}, g x_{n}\right)\right\} \\
&+\beta \min \left\{G\left(F\left(x_{n}, y_{n}\right), g x_{n-1}, g x_{n-1}\right), G\left(F\left(x_{n-1}, y_{n-1}\right), g x_{n-1}, g x_{n-1}\right),\right. \\
&\left.G\left(F\left(x_{n-1}, y_{n-1}\right), g x_{n-1}, g x_{n-1}\right)\right\} \\
&+\gamma \min \left\{G\left(F\left(x_{n}, y_{n}\right), g x_{n-1}, g x_{n-1}\right), G\left(F\left(x_{n-1}, y_{n-1}\right), g x_{n-1}, g x_{n-1}\right)\right. \\
&\left.G\left(F\left(x_{n-1}, y_{n-1}\right), g x_{n-1}, g x_{n-1}\right)\right\} \\
&+L \min \left\{G\left(F\left(x_{n}, y_{n}\right), g x_{n-1}, g x_{n-1}\right), G\left(F\left(x_{n-1}, y_{n-1}\right), g x_{n-1}, g x_{n-1}\right),\right. \\
&\left.G\left(F\left(x_{n-1}, y_{n-1}\right), g x_{n}, g x_{n}\right)\right\} \\
&=\alpha \min \left\{G\left(g x_{n+1}, g x_{n}, g x_{n}\right), G\left(g x_{n}, g x_{n}, g x_{n}\right), G\left(g x_{n}, g x_{n}, g x_{n}\right)\right\} \\
&+\beta \min \left\{G\left(g x_{n+1}, g x_{n-1}, g x_{n-1}\right), G\left(g x_{n}, g x_{n-1}, g x_{n-1}\right), G\left(g x_{n}, g x_{n-1}, g x_{n-1}\right)\right\} \\
&+\gamma \min \left\{G\left(g x_{n+1}, g x_{n-1}, g x_{n-1}\right), G\left(g x_{n}, g x_{n-1}, g x_{n-1}\right), G\left(g x_{n}, g x_{n-1}, g x_{n-1}\right)\right\} \\
&+L \min \left\{G\left(g x_{n+1}, g x_{n-1}, g x_{n-1}\right), G\left(g x_{n}, g x_{n-1}, g x_{n-1}\right), G\left(g x_{n}, g x_{n}, g x_{n}\right)\right\} \\
&(+\gamma) \min \left\{G\left(g x_{n+1}, g x_{n-1}, g x_{n-1}\right), G\left(g x_{n}, g x_{n-1}, g x_{n-1}\right)\right\} .
\end{aligned}
$$

Hence, we obtain

$$
G\left(g x_{n+1}, g x_{n}, g x_{n}\right) \leq(\beta+\gamma) G\left(g x_{n}, g x_{n-1}, g x_{n-1}\right) .
$$

Similarly, using (2.1) and (2.2), we can prove that

$$
G\left(g y_{n+1}, g y_{n}, g y_{n}\right) \leq(\beta+\gamma) G\left(g y_{n}, g y_{n-1}, g y_{n-1}\right) .
$$

Suppose that $\rho_{n}=G\left(g x_{n+1}, g x_{n}, g x_{n}\right)+G\left(g y_{n+1}, g y_{n}, g y_{n}\right)$ and $\delta=\beta+\gamma$, then $0 \leq \delta<1$. From (2.7) and (2.8), we have

$$
\begin{aligned}
\rho_{n} & =G\left(g x_{n+1}, g x_{n}, g x_{n}\right)+G\left(g y_{n+1}, g y_{n}, g y_{n}\right) \\
& \leq \delta\left(G\left(g x_{n}, g x_{n-1}, g x_{n-1}\right)+G\left(g y_{n}, g y_{n-1}, g y_{n-1}\right)\right)
\end{aligned}
$$




$$
\begin{aligned}
& =\delta \rho_{n-1} \leq \delta^{2} \rho_{n-2} \leq \cdots \\
& \leq \delta^{n} \rho_{0},
\end{aligned}
$$

which implies that

$$
\lim _{n \rightarrow \infty} \rho_{n}=\lim _{n \rightarrow \infty}\left[G\left(g x_{n+1}, g x_{n}, g x_{n}\right)+G\left(g y_{n+1}, g y_{n}, g y_{n}\right)\right]=0,
$$

and

$$
\lim _{n \rightarrow \infty} G\left(g x_{n+1}, g x_{n}, g x_{n}\right)=0 \quad \text { and } \quad \lim _{n \rightarrow \infty} G\left(g y_{n+1}, g y_{n}, g y_{n}\right)=0 .
$$

Next, we will prove that $\left\{g x_{n}\right\}$ and $\left\{g y_{n}\right\}$ are G-Cauchy sequences in $g(X)$.

In fact, for each $n, m \in \mathbb{N}, m>n$, from (G5) we have

$$
\begin{aligned}
G\left(g x_{m}, g x_{n}, g x_{n}\right) \leq & G\left(g x_{m}, g x_{m-1}, g x_{m-1}\right)+G\left(g x_{m-1}, g x_{m-2}, g x_{m-2}\right)+\cdots \\
& +G\left(g x_{n+1}, g x_{n}, g x_{n}\right)
\end{aligned}
$$

and

$$
\begin{aligned}
G\left(g y_{m}, g y_{n}, g y_{n}\right) \leq & G\left(g y_{m}, g y_{m-1}, g y_{m-1}\right)+G\left(g y_{m-1}, g y_{m-2}, g y_{m-2}\right)+\cdots \\
& +G\left(g y_{n+1}, g y_{n}, g y_{n}\right) .
\end{aligned}
$$

Therefore, combining inequalities (2.10), (2.11) and (2.9), we have

$$
\begin{aligned}
& G\left(g x_{m}, g x_{n}, g x_{n}\right)+G\left(g y_{m}, g y_{n}, g y_{n}\right) \\
& \quad \leq \rho_{m-1}+\rho_{m-2}+\cdots+\rho_{n} \\
& \quad=\left(\delta^{m-1}+\delta^{m-2}+\cdots+\delta^{n}\right) \rho_{0} \rightarrow 0 \quad \text { as } n, m \rightarrow \infty .
\end{aligned}
$$

This implies that $\left\{g x_{n}\right\}$ and $\left\{g y_{n}\right\}$ are G-Cauchy sequences in $g(X)$. Since $g(X)$ is a complete subspace of $X$, there exist $x, y \in X$ such that $g x_{n} \rightarrow g x$ and $g y_{n} \rightarrow g y$ as $n \rightarrow \infty$. Since $\left\{g x_{n}\right\}$ is a non-decreasing sequence and $\left\{g y_{n}\right\}$ is a non-increasing sequence, by the assumption conditions (i) and (ii), we have $g x_{n} \preceq g x$ and $g y_{n} \succeq g y$ for all $n \geq 0$.

It follows from (2.1) and (2.2) that

$$
\begin{aligned}
& G\left(g x_{n+1}, F(x, y), F(x, y)\right) \\
&= G\left(F\left(x_{n}, y_{n}\right), F(x, y), F(x, y)\right) \\
& \leq \alpha \min \left\{G\left(F\left(x_{n}, y_{n}\right), g x_{n}, g x_{n}\right), G\left(F(x, y), g x_{n}, g x_{n}\right), G\left(F(x, y), g x_{n}, g x_{n}\right)\right\} \\
&+\beta \min \left\{G\left(F\left(x_{n}, y_{n}\right), g x, g x\right), G(F(x, y), g x, g x), G(F(x, y), g x, g x)\right\} \\
&+\gamma \min \left\{G\left(F\left(x_{n}, y_{n}\right), g x, g x\right), G(F(x, y), g x, g x), G(F(x, y), g x, g x)\right\} \\
&+L \min \left\{G\left(F\left(x_{n}, y_{n}\right), g x, g x\right), G(F(x, y), g x, g x), G\left(F(x, y), g x_{n}, g x_{n}\right)\right\} \\
&= \alpha \min \left\{G\left(g x_{n+1}, g x_{n}, g x_{n}\right), G\left(F(x, y), g x_{n}, g x_{n}\right), G\left(F(x, y), g x_{n}, g x_{n}\right)\right\}
\end{aligned}
$$




$$
\begin{aligned}
& +(\beta+\gamma) \min \left\{G\left(g x_{n+1}, g x, g x\right), G(F(x, y), g x, g x)\right\} \\
& +L \min \left\{G\left(g x_{n+1}, g x, g x\right), G(F(x, y), g x, g x), G\left(F(x, y), g x_{n}, g x_{n}\right)\right\} .
\end{aligned}
$$

Taking the limit as $n \rightarrow \infty$ in the above inequality, we obtain $G(g x, F(x, y), F(x, y)) \leq 0$. Hence $G(g x, F(x, y), F(x, y))=0$, and so $g x=F(x, y)$.

Similarly, one can show that $g y=F(y, x)$. Thus we proved that $F$ and $g$ have a coupled coincidence point. This concludes the proof.

Theorem 2.2 Let $(X, \preceq)$ be a partially ordered set and $(X, G)$ be a complete $G$-metric space. Let $F: X \times X \rightarrow X$ and $g: X \rightarrow X$ be mappings such that $F$ has the mixed $g$-monotone property on $X$. Suppose there exist non-negative real numbers $\alpha, \beta, \gamma$ and $L$ with $\beta+\gamma<1$ such that

$$
\begin{aligned}
& G(F(x, y), F(u, v), F(w, z)) \\
& \leq \alpha \min \{G(F(x, y), g x, g x), G(F(u, v), g x, g x), G(F(w, z), g x, g x)\} \\
&+\beta \min \{G(F(x, y), g u, g u), G(F(u, v), g u, g u), G(F(w, z), g u, g u)\} \\
&+\gamma \min \{G(F(x, y), g w, g w), G(F(u, v), g w, g w), G(F(w, z), g w, g w)\} \\
&+L \min \{G(F(x, y), g u, g u), G(F(u, v), g w, g w), G(F(w, z), g x, g x)\}
\end{aligned}
$$

for all $(x, y),(u, v),(w, z) \in X \times X$ with $g(x) \preceq g(u) \preceq g(w)$ and $g(y) \succeq g(v) \succeq g(z)$. Further suppose $F(X \times X) \subset g(X)$ and $g$ is continuous non-decreasing and commutes with $F$, and also suppose either

(a) $F$ is continuous or

(b) $X$ has the following property:

(i) if a non-decreasing sequence $\left\{x_{n}\right\}$ in $X$ converges to $x \in X$, then $x_{n} \preceq x$ for all $n \in \mathbb{N}$

(ii) if a non-increasing sequence $\left\{y_{n}\right\}$ in $X$ converges to $y \in X$, then $y_{n} \succeq y$ for all $n \in \mathbb{N}$.

If there exist two elements $x_{0}, y_{0} \in X$ such that $g\left(x_{0}\right) \preceq F\left(x_{0}, y_{0}\right)$ and $g\left(y_{0}\right) \succeq F\left(y_{0}, x_{0}\right)$, then $F$ and $g$ have a coupled coincidence point. That is, there exists $(x, y) \in X \times X$ such that $F(x, y)=g(x)$ and $F(y, x)=g(y)$.

Proof Following the proof of Theorem 2.1, we will get two G-Cauchy sequences $\left\{g x_{n}\right\}$ and $\left\{g y_{n}\right\}$ in $X$ such that $\left\{g x_{n}\right\}$ is a non-decreasing sequence and $\left\{g y_{n}\right\}$ is a non-increasing sequence in $X$. Since $(X, G)$ is a complete $G$-metric space, there is $(x, y) \in X \times X$ such that $g x_{n} \rightarrow x$ and $g y_{n} \rightarrow y$.

Since $g$ is continuous, we have $g g x_{n} \rightarrow g x$ and $g g y_{n} \rightarrow g y$ as $n \rightarrow \infty$.

First, suppose that (a) holds, that is, $F$ is continuous. Then

$$
F\left(g x_{n}, g y_{n}\right) \rightarrow F(x, y) \quad \text { and } \quad F\left(g y_{n}, g x_{n}\right) \rightarrow F(y, x) .
$$

On the other hand, since $g$ commutes with $F$, we have

$$
F\left(g x_{n}, g y_{n}\right)=g F\left(x_{n}, y_{n}\right)=g g x_{n+1} \rightarrow g x \quad \text { as } n \rightarrow \infty
$$


and

$$
F\left(g y_{n}, g x_{n}\right)=g F\left(y_{n}, x_{n}\right)=g g y_{n+1} \rightarrow g y \quad \text { as } n \rightarrow \infty
$$

Therefore, by the uniqueness of limit, we get $g x=F(x, y)$ and $g y=F(y, x)$.

Second, suppose that (b) holds. Since $\left\{g x_{n}\right\}$ is a non-decreasing sequence such that $g x_{n} \rightarrow x,\left\{g y_{n}\right\}$ is a non-increasing sequence such that $g y_{n} \rightarrow y$ and $g$ is a non-decreasing function, by (i) and (ii) we get that $g\left(g x_{n}\right) \preceq g(x)$ and $g\left(g y_{n}\right) \geq g(y)$ hold for all $n \in \mathbb{N}$.

By (2.14), we have

$$
\begin{aligned}
G( & \left.g\left(g x_{n+1}\right), F(x, y), F(x, y)\right) \\
= & G\left(F\left(g x_{n}, g y_{n}\right), F(x, y), F(x, y)\right) \\
\leq & \alpha \min \left\{G\left(F\left(g x_{n}, g y_{n}\right), g\left(g x_{n}\right), g\left(g x_{n}\right)\right), G\left(F(x, y), g\left(g x_{n}\right), g\left(g x_{n}\right)\right),\right. \\
& \left.G\left(F(x, y), g\left(g x_{n}\right), g\left(g x_{n}\right)\right)\right\} \\
& +\beta \min \left\{G\left(F\left(g x_{n}, g y_{n}\right), g x, g x\right), G(F(x, y), g x, g x), G(F(x, y), g x, g x)\right\} \\
& +\gamma \min \left\{G\left(F\left(g x_{n}, g y_{n}\right), g x, g x\right), G(F(x, y), g x, g x), G(F(x, y), g x, g x)\right\} \\
& +L \min \left\{G\left(F\left(g x_{n}, g y_{n}\right), g x, g x\right), G(F(x, y), g x, g x), G\left(F(x, y), g\left(x_{n}\right), g\left(g x_{n}\right)\right)\right\} \\
=\alpha & \min \left\{G\left(g\left(g x_{n+1}\right), g\left(g x_{n}\right), g\left(g x_{n}\right)\right), G\left(F(x, y), g\left(g x_{n}\right), g\left(g x_{n}\right)\right),\right. \\
& \left.G\left(F(x, y), g\left(g x_{n}\right), g\left(g x_{n}\right)\right)\right\} \\
& +(\beta+\gamma) \min \left\{G\left(g\left(g x_{n+1}\right), g x, g x\right), G(F(x, y), g x, g x)\right\} \\
& +L \min \left\{G\left(g\left(g x_{n+1}\right), g x, g x\right), G(F(x, y), g x, g x), G\left(F(x, y), g\left(x_{n}\right), g\left(g x_{n}\right)\right)\right\} .
\end{aligned}
$$

Letting $n \rightarrow \infty$, we get $G(g x, F(x, y), F(x, y)) \leq 0$, which implies that $G(g x, F(x, y), F(x, y))=$ 0 , so that $g x=F(x, y)$.

Similarly, we can show that $g y=F(y, x)$. Thus we proved that $F$ and $g$ have a coupled coincidence point.

Remark 2.1 Theorems 2.1 and 2.2 generalize and extend the corresponding results in [29, Theorems 2.1 and 2.2] from partially ordered metric spaces to partially ordered G-metric spaces.

In Theorem 2.2, if we take $g=I$ ( $I$ is an identity mapping), then we have the following corollary.

Corollary 2.1 Let $(X, \preceq)$ be a partially ordered set and $(X, G)$ be a complete $G$-metric space. Let $F: X \times X \rightarrow X$ be a mapping such that $F$ has the mixed monotone property on $X$. Suppose there exist non-negative real numbers $\alpha, \beta, \gamma$ and $L$ with $\beta+\gamma<1$ such that

$$
\begin{aligned}
G( & F(x, y), F(u, v), F(w, z)) \\
\leq & \alpha \min \{G(F(x, y), x, x), G(F(u, v), x, x), G(F(w, z), x, x)\} \\
& +\beta \min \{G(F(x, y), u, u), G(F(u, v), u, u), G(F(w, z), u, u)\}
\end{aligned}
$$




$$
\begin{aligned}
& +\gamma \min \{G(F(x, y), w, w), G(F(u, v), w, w), G(F(w, z), w, w) \\
& +L \min \{G(F(x, y), u, u), G(F(u, v), w, w), G(F(w, z), x, x)\}
\end{aligned}
$$

for all $(x, y),(u, v),(w, z) \in X \times X$ with $x \preceq u \preceq w$ and $y \succeq v \succeq z$, and also suppose either

(a) $F$ is continuous or

(b) $X$ has the following property:

(i) if a non-decreasing sequence $\left\{x_{n}\right\}$ in $X$ converges to $x \in X$, then $x_{n} \preceq x$ for all $n \in \mathbb{N}$;

(ii) if a non-increasing sequence $\left\{y_{n}\right\}$ in $X$ converges to $y \in X$, then $y_{n} \succeq y$ for all $n \in \mathbb{N}$.

If there exist two elements $x_{0}, y_{0} \in X$ such that $g\left(x_{0}\right) \preceq F\left(x_{0}, y_{0}\right)$ and $g\left(y_{0}\right) \succeq F\left(y_{0}, x_{0}\right)$, then $F$ and $g$ have a coupled fixed point. That is, there exists $(x, y) \in X \times X$ such that $F(x, y)=x$ and $F(y, x)=y$.

Also, if we take $\alpha=\beta=\gamma=0$ in Theorem 2.2, then we get the following.

Corollary 2.2 Let $(X, \preceq)$ be a partially ordered set and $(X, G)$ be a complete $G$-metric space. Let $F: X \times X \rightarrow X$ and $g: X \rightarrow X$ be mappings such that $F$ has the mixed $g$-monotone property on $X$. Suppose there exists a non-negative real number $L$ such that

$$
\begin{aligned}
& G(F(x, y), F(u, v), F(w, z)) \\
& \quad \leq L \min \{G(F(x, y), g u, g u), G(F(u, v), g w, g w), G(F(w, z), g x, g x)\}
\end{aligned}
$$

for all $(x, y),(u, v),(w, z) \in X \times X$ with $g(x) \preceq g(u) \preceq g(w)$ and $g(y) \succeq g(v) \succeq g(z)$. Further suppose $F(X \times X) \subset g(X)$ and $g$ is continuous non-decreasing and commutes with $F$, and also suppose either

(a) $F$ is continuous or

(b) $X$ has the following property:

(i) if a non-decreasing sequence $\left\{x_{n}\right\}$ in $X$ converges to $x \in X$, then $x_{n} \preceq x$ for all $n \in \mathbb{N}$;

(ii) if a non-increasing sequence $\left\{y_{n}\right\}$ in $X$ converges to $y \in X$, then $y_{n} \succeq y$ for all $n \in \mathbb{N}$.

If there exist two elements $x_{0}, y_{0} \in X$ such that $g\left(x_{0}\right) \preceq F\left(x_{0}, y_{0}\right)$ and $g\left(y_{0}\right) \succeq F\left(y_{0}, x_{0}\right)$, then $F$ and $g$ have a coupled coincidence point. That is, there exists $(x, y) \in X \times X$ such that $F(x, y)=g(x)$ and $F(y, x)=g(y)$.

Corollary 2.3 Let $(X, \preceq)$ be a partially ordered set and $(X, G)$ be a complete $G$-metric space. Let $F: X \times X \rightarrow X$ and $g: X \rightarrow X$ be mappings such that $F$ has the mixed $g$-monotone property on $X$. Suppose there exist non-negative real numbers $\alpha, \beta, \gamma$ and $L$ with $\beta+\gamma<1$ such that

$$
\begin{aligned}
& G(F(x, y), F(u, v), F(w, z)) \\
& \leq(\alpha+\beta+\gamma) \min \{G(F(x, y), g x, g x), G(F(u, v), g x, g x), G(F(w, z), g x, g x), \\
& \quad G(F(x, y), g u, g u), G(F(u, v), g u, g u), G(F(w, z), g u, g u), G(F(x, y), g w, g w),
\end{aligned}
$$




$$
\begin{aligned}
& G(F(u, v), g w, g w), G(F(w, z), g w, g w)\} \\
& +L \min \{G(F(x, y), g u, g u), G(F(u, v), g w, g w), G(F(w, z), g x, g x)\}
\end{aligned}
$$

for all $(x, y),(u, v),(w, z) \in X \times X$ with $g(x) \preceq g(u) \preceq g(w)$ and $g(y) \succeq g(v) \succeq g(z)$. Further suppose $F(X \times X) \subset g(X)$ and $g$ is continuous non-decreasing and commutes with $F$, and also suppose either

(a) $F$ is continuous or

(b) $X$ has the following property:

(i) if a non-decreasing sequence $\left\{x_{n}\right\}$ in $X$ converges to $x \in X$, then $x_{n} \preceq x$ for all $n \in \mathbb{N}$;

(ii) if a non-increasing sequence $\left\{y_{n}\right\}$ in $X$ converges to $y \in X$, then $y_{n} \succeq y$ for all $n \in \mathbb{N}$.

If there exist two elements $x_{0}, y_{0} \in X$ such that $g\left(x_{0}\right) \preceq F\left(x_{0}, y_{0}\right)$ and $g\left(y_{0}\right) \succeq F\left(y_{0}, x_{0}\right)$, then $F$ and $g$ have a coupled coincidence point. That is, there exists $(x, y) \in X \times X$ such that $F(x, y)=g(x)$ and $F(y, x)=g(y)$.

Proof By noting that if $\alpha, \beta$ and $\gamma$ are non-negative real numbers, from (2.18) we have

$$
\begin{aligned}
G( & (x, y), F(u, v), F(w, z)) \\
\leq & (\alpha+\beta+\gamma) \min \{G(F(x, y), g x, g x), G(F(u, v), g x, g x), G(F(w, z), g x, g x), \\
& G(F(x, y), g u, g u), G(F(u, v), g u, g u), G(F(w, z), g u, g u), G(F(x, y), g w, g w), \\
& G(F(u, v), g w, g w), G(F(w, z), g w, g w)\} \\
& +L \min \{G(F(x, y), g u, g u), G(F(u, v), g w, g w), G(F(w, z), g x, g x)\} \\
\leq & \alpha \min \{G(F(x, y), g x, g x), G(F(u, v), g x, g x), G(F(w, z), g x, g x)\} \\
& +\beta \min \{G(F(x, y), g u, g u), G(F(u, v), g u, g u), G(F(w, z), g u, g u)\} \\
& +\gamma \min \{G(F(x, y), g w, g w), G(F(u, v), g w, g w), G(F(w, z), g w, g w)\} \\
& +L \min \{G(F(x, y), g u, g u), G(F(u, v), g w, g w), G(F(w, z), g x, g x)\} .
\end{aligned}
$$

From Theorem 2.2, we see that $F$ and $g$ have a coupled coincidence point $(x, y) \in X \times X$; that is, $F(x, y)=g x$ and $F(y, x)=g y$.

Remark 2.2 Corollaries 2.1, 2.2 and 2.3 generalize and extend the corresponding results in [29, Corollaries 2.1, 2.2 and 2.3] from partially ordered metric spaces to partially ordered G-metric spaces.

Now we will prove the existence and uniqueness theorem of a coupled common fixed point. Note that if $(X \preceq)$ is a partially ordered set, then we endow the product space $X \times X$ with the following partial order:

$$
\text { for }(x, y),(u, v) \in X \times X, \quad(u, v) \preceq(x, y) \quad \Leftrightarrow \quad x \succeq u, \quad y \preceq v \text {. }
$$

Theorem 2.3 In addition to the hypotheses of Theorem 2.1, suppose that $L=0$ and for every $(x, y),\left(y^{*}, x^{*}\right) \in X \times X$, there exists $a(u, v) \in X \times X$ such that $(F(u, v), F(v, u))$ is comparable to $(F(x, y), F(y, x))$ and $\left(F\left(x^{*}, y^{*}\right), F\left(y^{*}, x^{*}\right)\right)$. Then $F$ and $g$ have a unique coupled 
common fixed point; that is, there exists a unique $(x, y) \in X \times X$ such that $x=g x=F(x, y)$ and $y=g y=F(y, x)$.

Proof From Theorem 2.1, the set of coupled coincidence points of $F$ and $g$ is nonempty. Suppose $(x, y)$ and $\left(x^{*}, y^{*}\right)$ are coupled coincidence points of $F$ and $g$, that is, $g x=F(x, y)$, $g y=F(y, x), g x^{*}=F\left(x^{*}, y^{*}\right)$ and $g y^{*}=F\left(y^{*}, x^{*}\right)$, then

$$
g(x)=g\left(x^{*}\right) \text { and } g(y)=g\left(y^{*}\right) .
$$

By assumption, there exists $(u, v) \in X \times X$ such that $(F(u, v), F(v, u))$ is comparable with $(F(x, y), F(y, x))$ and $\left(F\left(x^{*}, y^{*}\right), F\left(y^{*}, x^{*}\right)\right)$. Put $u_{0}=u, v_{0}=v$ and choose $u_{1}, v_{1} \in X$ so that $g\left(u_{1}\right)=F\left(u_{0}, v_{0}\right)$ and $g\left(v_{1}\right)=F\left(v_{0}, u_{0}\right)$. Then, similarly as in the proof of Theorem 2.1, we can inductively define sequences $\left\{g\left(u_{n}\right)\right\}$ and $\left\{g\left(v_{n}\right)\right\}$ such that

$$
g\left(u_{n+1}\right)=F\left(u_{n}, v_{n}\right) \quad \text { and } \quad g\left(v_{n+1}\right)=F\left(v_{n}, u_{n}\right) \quad \forall n \in \mathbb{N} .
$$

Further, set $x_{0}=x, y_{0}=y, x_{0}^{*}=x^{*}$ and $y_{0}^{*}=y^{*}$. In the same way, we define the sequences $\left\{g\left(x_{n}\right)\right\},\left\{g\left(y_{n}\right)\right\},\left\{g\left(x_{n}^{*}\right)\right\}$ and $\left\{g\left(y_{n}^{*}\right)\right\}$. It is easy to show that

$$
g\left(x_{n}\right) \rightarrow F(x, y), \quad g\left(y_{n}\right) \rightarrow F(y, x), \quad g\left(x_{n}^{*}\right) \rightarrow F\left(x^{*}, y^{*}\right), \quad g\left(y_{n}^{*}\right) \rightarrow F\left(y^{*}, x^{*}\right) .
$$

Since

$$
(F(x, y), F(y, x))=\left(g\left(x_{1}\right), g\left(y_{1}\right)\right)=(g(x), g(y))
$$

and

$$
(F(u, v), F(v, u))=\left(g\left(u_{1}\right), g\left(v_{1}\right)\right)
$$

are comparable, we see that $g(x) \preceq g\left(u_{1}\right)$ and $g(y) \succeq g\left(v_{1}\right)$. It is easy to show that $(g(x), g(y))$ and $\left(g\left(u_{n}\right), g\left(v_{n}\right)\right)$ are comparable, that is, $g(x) \preceq g\left(u_{n}\right)$ and $g(y) \succeq g\left(v_{n}\right)$ for all $n \geq 1$. Thus from (2.1), we have

$$
\begin{aligned}
& G\left(g x, g u_{n+1}, g u_{n+1}\right) \\
&= G\left(F(x, y), F\left(u_{n}, v_{n}\right), F\left(u_{n}, v_{n}\right)\right) \\
& \leq\left.\alpha \min \left\{G(F(x, y), g x, g x), F\left(u_{n}, v_{n}\right), g x, g x\right), G\left(F\left(u_{n}, v_{n}\right), g x, g x\right)\right\} \\
&\left.+\beta \min \left\{G\left(F(x, y), g u_{n}, g u_{n}\right), G\left(F\left(u_{n}, v_{n}\right), g u_{n}, g u_{n}\right), F\left(u_{n}, v_{n}\right), g u_{n}, g u_{n}\right)\right\} \\
&+\gamma \min \left\{G\left(F(x, y), g u_{n}, g u_{n}\right), G\left(F\left(u_{n}, v_{n}\right), g u_{n}, g u_{n}\right), G\left(F\left(u_{n}, v_{n}\right), g u_{n}, g u_{n}\right)\right\} .
\end{aligned}
$$

Since $F(x, y)=g(x)$ and $g\left(u_{n+1}\right)=F\left(u_{n}, v_{n}\right)$, we have

$$
\begin{aligned}
& G\left(g x, g u_{n+1}, g u_{n+1}\right) \\
& \quad \leq(\beta+\gamma) \min \left\{G\left(g x, g u_{n}, g u_{n}\right), G\left(g u_{n+1}, g u_{n}, g u_{n}\right)\right\} .
\end{aligned}
$$


Therefore, we have

$$
G\left(g x, g u_{n+1}, g u_{n+1}\right) \leq(\beta+\gamma) G\left(g x, g u_{n}, g u_{n}\right) .
$$

Similarly, using (2.1), $g(y)=y$ and $g\left(v_{n+1}\right)=F\left(v_{n}, u_{n}\right)$, we can prove that

$$
G\left(g y, g v_{n+1}, g v_{n+1}\right) \leq(\beta+\gamma) G\left(g y, g v_{n}, g v_{n}\right) .
$$

From (2.21) and (2.22), we have

$$
\begin{aligned}
& G\left(g x, g u_{n+1}, g u_{n+1}\right)+G\left(g y, g v_{n+1}, g v_{n+1}\right) \\
& \quad \leq(\beta+\gamma)\left[G\left(g x, g u_{n}, g u_{n}\right)+G\left(g y, g v_{n}, g v_{n}\right)\right] \\
& \quad \leq(\beta+\gamma)^{2}\left[G\left(g x, g u_{n-1}, g u_{n-1}\right)+G\left(g y, g v_{n-1}, g v_{n-1}\right)\right] \\
& \quad \leq \cdots \\
& \quad \leq(\beta+\gamma)^{n+1}\left[G\left(g x, g u_{0}, g u_{0}\right)+G\left(g y, g v_{0}, g v_{0}\right)\right] .
\end{aligned}
$$

Taking the limit as $n \rightarrow \infty$, we get

$$
\lim _{n \rightarrow \infty}\left[G\left(g x, g u_{n}, g u_{n}\right)+G\left(g y, g v_{n}, g v_{n}\right)\right]=0,
$$

which implies that

$$
\lim _{n \rightarrow \infty} G\left(g x, g u_{n}, g u_{n}\right)=\lim _{n \rightarrow \infty} G\left(g y, g v_{n}, g v_{n}\right)=0 .
$$

Similarly, we show that

$$
\lim _{n \rightarrow \infty} G\left(g x^{*}, g u_{n}, g u_{n}\right)=\lim _{n \rightarrow \infty} G\left(g y^{*}, g v_{n}, g v_{n}\right)=0 .
$$

By the rectangle inequality (G5), Proposition 1.3, (2.23) and (2.24), we obtain

$$
\begin{aligned}
G\left(g x, g x^{*}, g x^{*}\right) & \leq G\left(g x, g u_{n}, g u_{n}\right)+G\left(g u_{n}, g x^{*}, g x^{*}\right) \\
& \leq\left(g x, g u_{n}, g u_{n}\right)+2 G\left(g x^{*}, g u_{n}, g u_{n}\right) \\
& \rightarrow 0 \quad \text { as } n \rightarrow \infty,
\end{aligned}
$$

and

$$
\begin{aligned}
G\left(g y, g y^{*}, g x^{*}\right) & \leq G\left(g y, g v_{n}, g v_{n}\right)+G\left(g v_{n}, g y^{*}, g y^{*}\right) \\
& \leq\left(g y, g v_{n}, g v_{n}\right)+2 G\left(g y^{*}, g v_{n}, g v_{n}\right) \\
& \rightarrow 0 \quad \text { as } n \rightarrow \infty .
\end{aligned}
$$

It implies that $g(x)=g\left(x^{*}\right)$ and $g(y)=g\left(y^{*}\right)$. Thus we have (2.20) holds. This implies that $(g(x), g(y))=\left(g\left(x^{*}\right), g\left(y^{*}\right)\right)$. 
Since $g(x)=F(x, y)$ and $g(y)=F(y, x)$, by the commutativity of $F$ and $g$, we have

$$
g(g x)=g(F(x, y))=F(g x, g y) \quad \text { and } \quad g(g y)=g(F(y, x))=F(g y, g x) .
$$

Denote $g(x)=z, g(y)=w$. Then from (2.25) we have

$$
g(z)=F(z, w) \quad \text { and } \quad g(w)=F(w, z) .
$$

Thus $(z, w)$ is a coupled coincidence point of $F$ and $g$. Then from (2.25) with $x^{*}=z$ and $y^{*}=w$ it follows $g(z)=g(x)$ and $g(w)=g(y)$, that is,

$$
g(z)=z \quad \text { and } \quad g(w)=w
$$

From (2.26) and (2.27), we get

$$
z=g(z)=F(z, w) \quad \text { and } \quad w=g(w)=F(w, z) .
$$

Therefore, $(z, w)$ is a coupled common fixed point of $F$ and $g$. To prove the uniqueness, assume that $(p, q)$ is another coupled common fixed point, then by (2.25) we have $p=$ $g(p)=g(z)=z$ and $q=g(q)=g(w)=w$. This completes the proof of Theorem 2.3.

In Theorem 2.3, if we take $g=I$ ( $I$ is an identity mapping), then we have the following corollary.

Corollary 2.4 In addition to the hypotheses of Corollary 2.1, suppose that $L=0$, and for every $(x, y),\left(y^{*}, x^{*}\right) \in X \times X$, there exists a $(u, v) \in X \times X$ such that $(F(u, v), F(v, u))$ is comparable to $(F(x, y), F(y, x))$ and $\left(F\left(x^{*}, y^{*}\right), F\left(y^{*}, x^{*}\right)\right)$. Then $F$ has a unique coupled fixed point; that is, there exists a unique $(x, y) \in X \times X$ such that $x=F(x, y)$ and $y=F(y, x)$.

Theorem 2.4 In addition to the hypotheses of Theorem 2.1, if $g x_{0}$ and gy $y_{0}$ are comparable and $L=0$, then $F$ and $g$ have a coupled coincidence point $(x, y)$ such that $g x=F(x, y)=$ $F(y, x)=g y$.

Proof By Theorem 2.1 we construct two sequences $\left\{x_{n}\right\}$ and $\left\{y_{n}\right\}$ in $X$ such that $g x_{n} \rightarrow g x$ and $g y_{n} \rightarrow g y$, where $(x, y)$ is a coincidence point of $F$ and $g$. Suppose $g x_{0} \preceq g y_{0}$, then it is an easy matter to show that $g x_{n} \preceq g y_{n}$ for all $n \in \mathbb{N}$. Thus, by (2.1) we have

$$
\begin{aligned}
& G\left(g x_{n}, g y_{n}, g y_{n}\right) \\
&= G\left(F\left(x_{n-1}, y_{n-1}\right), F\left(y_{n-1}, x_{n-1}\right), F\left(y_{n-1}, x_{n-1}\right)\right) \\
& \leq \alpha \min \left\{G\left(F\left(x_{n-1}, y_{n-1}\right), g x_{n-1}, g x_{n-1}\right), G\left(F\left(y_{n-1}, x_{n-1}\right), g x_{n-1}, g x_{n-1}\right),\right. \\
&\left.G\left(F\left(y_{n-1}, x_{n-1}\right), g x_{n-1}, g x_{n-1}\right)\right\} \\
&+\beta \min \left\{G\left(F\left(x_{n-1}, y_{n-1}\right), g y_{n-1}, g y_{n-1}\right), G\left(F\left(y_{n-1}, x_{n-1}\right), g y_{n-1}, g y_{n-1}\right),\right. \\
&\left.G\left(F\left(y_{n-1}, x_{n-1}\right), g y_{n-1}, g y_{n-1}\right)\right\} \\
&+\gamma \min \left\{G\left(F\left(x_{n-1}, y_{n-1}\right), g y_{n-1}, g y_{n-1}\right), G\left(F\left(y_{n-1}, x_{n-1}\right), g y_{n-1}, g y_{n-1}\right),\right.
\end{aligned}
$$




$$
\begin{aligned}
& \left.G\left(F\left(y_{n-1}, x_{n-1}\right), g y_{n-1}, g y_{n-1}\right)\right\} \\
= & \alpha \min \left\{G\left(g x_{n}, g x_{n-1}, g x_{n-1}\right), G\left(g y_{n}, g x_{n-1}, g x_{n-1}\right)\right\} \\
& +\beta \min \left\{G\left(g x_{n}, g y_{n-1}, g y_{n-1}\right), G\left(g y_{n}, g y_{n-1}, g y_{n-1}\right)\right\} \\
& +\gamma \min \left\{G\left(g x_{n}, g y_{n-1}, g y_{n-1}\right), G\left(g y_{n}, g y_{n-1}, g y_{n-1}\right)\right\} .
\end{aligned}
$$

By taking the limit as $n \rightarrow \infty$, we get $G(g x, g y, g y)=0$. Hence $F(x, y)=g x=g y=F(y, x)$.

A similar argument can be used if $g y_{0} \preceq g x_{0}$. This completes the proof of Theorem 2.4.

In Theorem 2.4, if we take $g=I$ ( $I$ is an identity mapping), then we have the following corollary.

Corollary 2.5 In addition to the hypotheses of Theorem 2.1, if $x_{0}$ and $y_{0}$ are comparable and $L=0$, then $F$ has a coupled coincidence point of the form $(x, x)$.

Remark 2.3 Theorems 2.3 and 2.4 generalize and extend the corresponding results in [29, Theorems 2.3 and 2.4] from partially ordered metric spaces to partially ordered G-metric spaces.

Remark 2.4 Corollaries 2.4 and 2.5 generalize and extend the corresponding results in [29, Corollaries 2.4 and 2.5] from partially ordered metric spaces to partially ordered G-metric spaces.

Now, we introduce an example to support Theorem 2.1.

Example 2.1 Let $X=[0,1]$, then $(X, \leq)$ is a partially ordered set with a natural ordering of real numbers. Let $G(x, y, z)=|x-y|+|y-z|+|z-x|$ for all $x, y, z \in X$. Set $F$ and $g$ as

$$
\begin{aligned}
& g: X \rightarrow X, \quad g(x)=x^{2} \quad \text { and } \\
& F: X \times X \rightarrow X, \quad F(x, y)= \begin{cases}\frac{x^{2}-y^{2}}{16}, & x \geq y, \\
0, & x<y .\end{cases}
\end{aligned}
$$

Then

(1) $(X, G)$ is a complete $G$-metric space;

(2) $g(X)=X$ is complete;

(3) $F(X \times X) \subset g(X)=X$;

(4) $X$ satisfies (i) and (ii) of Theorem 2.1;

(5) $F$ has the mixed $g$-monotone property;

(6) For any $L \in[0, \infty), F$ and $g$ satisfy

$$
\begin{aligned}
G( & F(x, y), F(u, v), F(w, z)) \\
\leq & \frac{1}{8} \min \{G(F(x, y), g x, g x), G(F(u, v), g x, g x), G(F(w, z), g x, g x)\} \\
& +\frac{1}{8} \min \{G(F(x, y), g u, g u), G(F(u, v), g u, g u), G(F(w, z), g u, g u)\}
\end{aligned}
$$




$$
\begin{aligned}
& +\frac{1}{8} \min \{G(F(x, y), g w, g w), G(F(u, v), g w, g w), G(F(w, z), g w, g w)\} \\
& +L \min \{G(F(x, y), g u, g u), G(F(u, v), g w, g w), G(F(w, z), g x, g x)\}
\end{aligned}
$$

for all $(x, y),(u, v),(w, z) \in X \times X$ with $g x \leq g u \leq g w$ and $g y \geq g v \geq g z$. Thus by Theorem 2.1, $F$ and $g$ have a coupled coincidence point. Moreover, $(0,0)$ is a coupled fixed point of $F$.

Proof The proofs of (1)-(5) are clear. The proof of (6) is divided into the following cases.

Case 1. If $x \geq y$. In this case, we have $z \leq v \leq y \leq x \leq u \leq w$, and so

$$
F(x, y)=\frac{x^{2}-y^{2}}{16}, \quad F(u, v)=\frac{u^{2}-v^{2}}{16}, \quad F(w, z)=\frac{w^{2}-z^{2}}{16} .
$$

Hence, we get

$$
\begin{aligned}
G( & F(x, y), F(u, v), F(w, z)) \\
= & G\left(\frac{x^{2}-y^{2}}{16}, \frac{u^{2}-v^{2}}{16}, \frac{w^{2}-z^{2}}{16}\right) \\
= & \frac{w^{2}-z^{2}-\left(x^{2}-y^{2}\right)}{8} \leq \frac{w^{2}}{8} \leq \frac{15 w^{2}}{64} \leq \frac{15 w^{2}+w^{2}-x^{2}+y^{2}}{64} \\
= & \frac{1}{8} \cdot \frac{16 w^{2}-x^{2}+y^{2}}{8}=\frac{1}{8} G\left(\frac{x^{2}-y^{2}}{16}, w^{2}, w^{2}\right) \\
= & \frac{1}{8} \min \left\{G\left(\frac{x^{2}-y^{2}}{16}, w^{2}, w^{2}\right), G\left(\frac{u^{2}-v^{2}}{16}, w^{2}, w^{2}\right), G\left(\frac{w^{2}-z^{2}}{16}, w^{2}, w^{2}\right)\right\} \\
= & \frac{1}{8} \min \{G(F(x, y), g w, g w), G(F(u, v), g w, g w), G(F(w, z), g w, g w)\} \\
\leq & \frac{1}{8} \min \{G(F(x, y), g x, g x), G(F(u, v), g x, g x), G(F(w, z), g x, g x)\} \\
& +\frac{1}{8} \min \{G(F(x, y), g u, g u), G(F(u, v), g u, g u), G(F(w, z), g u, g u)\} \\
& +\frac{1}{8} \min \{G(F(x, y), g w, g w), G(F(u, v), g w, g w), G(F(w, z), g w, g w)\} \\
& +L \min \{G(F(x, y), g u, g u), G(F(u, v), g w, g w), G(F(w, z), g x, g x)\} .
\end{aligned}
$$

Case 2. $x<y$. We divide the study in two sub-cases:

(a) If $u \geq v$, then $z \leq v \leq u \leq w$, so $w \geq z$. Therefore, we get

$$
F(x, y)=0, \quad F(u, v)=\frac{u^{2}-v^{2}}{16}, \quad F(w, z)=\frac{w^{2}-z^{2}}{16} .
$$

Hence, we have

$$
\begin{aligned}
& G(F(x, y), F(u, v), F(w, z)) \\
& \quad=G\left(0, \frac{u^{2}-v^{2}}{16}, \frac{w^{2}-z^{2}}{16}\right) \\
& \quad=\frac{w^{2}-z^{2}}{8} \leq \frac{w^{2}}{8} \leq \frac{15 w^{2}}{64} \leq \frac{15 w^{2}+w^{2}-u^{2}+v^{2}}{64}
\end{aligned}
$$




$$
\begin{aligned}
= & \frac{1}{8} \cdot \frac{16 w^{2}-u^{2}+v^{2}}{8}=\frac{1}{8} G\left(\frac{u^{2}-v^{2}}{16}, w^{2}, w^{2}\right) \\
= & \frac{1}{8} \min \left\{G\left(0, w^{2}, w^{2}\right), G\left(\frac{u^{2}-v^{2}}{16}, w^{2}, w^{2}\right), G\left(\frac{w^{2}-z^{2}}{16}, w^{2}, w^{2}\right)\right\} \\
= & \frac{1}{8} \min \{G(F(x, y), g w, g w), G(F(u, v), g w, g w), G(F(w, z), g w, g w)\} \\
\leq & \frac{1}{8} \min \{G(F(x, y), g x, g x), G(F(u, v), g x, g x), G(F(w, z), g x, g x)\} \\
& +\frac{1}{8} \min \{G(F(x, y), g u, g u), G(F(u, v), g u, g u), G(F(w, z), g u, g u)\} \\
& +\frac{1}{8} \min \{G(F(x, y), g w, g w), G(F(u, v), g w, g w), G(F(w, z), g w, g w)\} \\
& +L \min \{G(F(x, y), g u, g u), G(F(u, v), g w, g w), G(F(w, z), g x, g x)\} .
\end{aligned}
$$

(b) If $u<v$, hence $F(x, y)=0=F(u, v)$; the case where $w<z$ is obvious because we get $F(w, z)=0$. If $w \geq z$, we have $F(w, z)=\frac{w^{2}-z^{2}}{16}$. Therefore

$$
\begin{aligned}
G( & F(x, y), F(u, v), F(w, z)) \\
= & G\left(0,0, \frac{w^{2}-z^{2}}{16}\right) \\
= & \frac{w^{2}-z^{2}}{8} \leq \frac{w^{2}}{8} \leq \frac{15 w^{2}}{64} \leq \frac{15 w^{2}+z^{2}}{64} \\
= & \frac{1}{8} \cdot \frac{15 w^{2}+z^{2}}{8}=\frac{1}{8} G\left(\frac{w^{2}-z^{2}}{16}, w^{2}, w^{2}\right) \\
= & \frac{1}{8} \min \left\{G\left(0, w^{2}, w^{2}\right), G\left(0, w^{2}, w^{2}\right), G\left(\frac{w^{2}-z^{2}}{16}, w^{2}, w^{2}\right)\right\} \\
= & \frac{1}{8} \min \{G(F(x, y), g w, g w), G(F(u, v), g w, g w), G(F(w, z), g w, g w)\} \\
\leq & \frac{1}{8} \min \{G(F(x, y), g x, g x), G(F(u, v), g x, g x), G(F(w, z), g x, g x)\} \\
& +\frac{1}{8} \min \{G(F(x, y), g u, g u), G(F(u, v), g u, g u), G(F(w, z), g u, g u)\} \\
& +\frac{1}{8} \min \{G(F(x, y), g w, g w), G(F(u, v), g w, g w), G(F(w, z), g w, g w)\} \\
& +L \min \{G(F(x, y), g u, g u), G(F(u, v), g w, g w), G(F(w, z), g x, g x)\} .
\end{aligned}
$$

In all the above cases, inequality (2.1) of Theorem 2.1 is satisfied for $\alpha=\beta=\gamma=\frac{1}{8}$ and any $L \geq 0$. All the required hypotheses of Theorem 2.1 are satisfied. Clearly, $F$ and $g$ have a coupled coincidence point. Moreover, $(0,0)$ is a coupled fixed point of $F$.

\section{Competing interests}

The authors declare that they have no competing interests. 


\section{Acknowledgements}

The authors are grateful to the editor and the reviewer for suggestions which improved the contents of the article. This work is supported by the National Natural Science Foundation of China $(11071169,11271105)$ and the Natural Science Foundation of Zhejiang Province (Y6110287, LY12A01030)

\section{Received: 7 November 2012 Accepted: 26 February 2013 Published: 20 March 2013}

\section{References}

1. Ran, ACM, Reurings, MCB: A fixed point theorem in partially ordered sets and some applications to matrix equations. Proc. Am. Math. Soc. 132(5), 1435-1443 (2004)

2. Nieto, JJ, Rodríguez-López, R: Contractive mapping theorems in partially ordered sets and applications to ordinary differential equations. Order 22, 223-239 (2005). doi:10.1007/s11083-005-90185-5

3. Nieto, JJ, Rodríguez-López, R: Existence and uniqueness of fixed point in partially ordered sets and applications to ordinary differential equations. Acta Math. Sin. Engl. Ser. 23(12), 2205-2212 (2007)

4. Tarski, A: A lattice-theoretical fixpoint theorem and its applications. Pac. J. Math. 5(2), 285-309 (1955)

5. Nieto, JJ, Rodríguez-López, R: Existence of extremal solutions for quadratic fuzzy equations. Fixed Point Theory Appl. 2005(3), 321-342 (2005)

6. Amini-Harandi, A, Emami, H: A fixed point theorem for contraction type maps in partially ordered metric spaces and application to ordinary differential equations. Nonlinear Anal. 72(5), 2238-2242 (2010)

7. Harjani, J, Sadarangani, K: Generalized contractions in partially ordered metric spaces and applications to ordinary differential equations. Nonlinear Anal. 72(3-4), 1188-1197 (2010)

8. Nashine, HK, Samet, B, Vetro, C: Fixed point theorems in partially ordered metric spaces and existence results for integral equations. Numer. Funct. Anal. Optim. 33(11), 1304-1320 (2012). doi:10.1080/01630563.2012.675395

9. Harjani, J, Sadarangani, K: Fixed point theorems for monotone generalized contractions in partially ordered metric spaces and applications to integral equations. J. Convex Anal. 19(3), 853-864 (2012)

10. Kostrykin, V, Oleynik, A: An intermediate value theorem for monotone operators in ordered Banach spaces. Fixed Point Theory Appl. 2012, Article ID 211 (2012). doi:10.1186/1687-1812-2012-211

11. Chifu, C, Petruşel, G: Generalized contractions in metric spaces endowed with a graph. Fixed Point Theory Appl. 2012 Article ID 161 (2012). doi:10.1186/1687-1812-2012-161

12. Nieto, JJ, Pouso, RL, Rodríguez-López, R: Fixed point theorems in ordered abstract spaces. Proc. Am. Math. Soc. 135 2505-2517 (2007)

13. Amini-Harandi, A: Metric-like spaces, partial metric spaces and fixed points. Fixed Point Theory Appl. 2012, Article ID 204 (2012). doi:10.1186/1687-1812-2012-204

14. Ali, B, Abbas, M: Suzuki type fixed point theorem for fuzzy mappings in ordered metric spaces. Fixed Point Theory Appl. 2013, Article ID 9 (2013). doi:10.1186/1687-1812-2013-9

15. Agarwal, RP, El-Gebeily, MA, O’Regan, D: Generalized contractions in partially ordered metric spaces. Appl. Anal. 87(1) 109-116 (2008)

16. Ćirić, LB, Cakic, N, Rajovic, M, Ume, JS: Monotone generalized nonlinear contractions in partially ordered metric spaces. Fixed Point Theory Appl. 2008, Article ID 131294 (2008)

17. O'Regan, D, Petrutel, A: Fixed point theorems for generalized contractions in ordered metric spaces. J. Math. Anal. Appl. 341(2), 1241-1252 (2008)

18. Altun, I, Simsek, H: Some fixed point theorems on ordered metric spaces and application. Fixed Point Theory Appl. 2010, Article ID 621492 (2010)

19. Nashine, HK, Altun, l: Fixed point theorems for generalized weakly contractive condition in ordered metric spaces. Fixed Point Theory Appl. 2011, Article ID 132367 (2011)

20. Nashine, HK, Samet, B: Fixed point results for mappings satisfying $(\psi, \phi)$-weakly contractive condition in partially ordered metric spaces. Nonlinear Anal. 74, 2201-2209 (2011)

21. Nashine, HK, Samet, B, Vetro, C: Monotone generalized nonlinear contractions and fixed point theorems in ordered metric spaces. Math. Comput. Model. 54, 712-720 (2011)

22. Bhaskar, TG, Lakshmikantham, V: Fixed point theorems in partially ordered metric spaces and applications. Nonlinear Anal. 65, 1379-1393 (2006)

23. Lakshmikanthama, V, Ćirić, LB: Coupled fixed point theorems for nonlinear contractions in partially ordered metric spaces. Nonlinear Anal. 70, 4341-4349 (2009)

24. Samet, B, Vetro, C: Coupled fixed point, F-invariant set and fixed point of N-order. Ann. Funct. Anal. 1(2), 46-56 (2010)

25. Samet, B, Vetro, C: Coupled fixed point theorems for multi-valued nonlinear contraction mappings in partially ordered metric spaces. Nonlinear Anal. 74(12), 4260-4268 (2011)

26. Aydi, H, Samet, B, Vetro, C: Coupled fixed point results in cone metric spaces for compatible mappings. Fixed Point Theory Appl. 2011, Article ID 15 (2011). doi:10.1186/1687-1812-2011-27

27. Nashine, HK, Samet, B, Vetro, C: Coupled coincidence points for compatible mappings satisfying mixed monotone property. J. Nonlinear Sci. Appl. 5(2), 104-114 (2012)

28. Samet, B: Coupled fixed point theorems for s generalized Meir-Keeler contraction in partially ordered metric spaces. Nonlinear Anal. 72, 4508-4517 (2010)

29. Nashine, HK, Shatanawi, W: Coupled common fixed point theorems for a pair commuting mappings in partially ordered complete metric spaces. Comput. Math. Appl. 62, 1984-1993 (2011)

30. Mustafa, Z, Sims, B: A new approach to a generalized metric space. J. Nonlinear Convex Anal. 7(2), $289-297$ (2006)

31. Mustafa, Z, Obiedat, H, Awawdeh, F: Some fixed point theorems for mappings on complete G-metric space. Fixed Point Theory Appl. 2008, Article ID 189870 (2008)

32. Mustafa, Z, Sims, B: Fixed point theorems for contractive mappings in complete G-metric spaces. Fixed Point Theory Appl. 2009, Article ID 917175 (2009)

33. Abbas, $\mathrm{M}$, Rhoades, $\mathrm{BE}$ : Common fixed point results for noncommuting mappings without continuity in generalized metric spaces. Appl. Math. Comput. 215, 262-269 (2009)

34. Shatanawi, W: Fixed point theory for contractive mappings satisfying $\Phi$-maps in $G$-metric spaces. Fixed Point Theory Appl. 2010, Article ID 181650 (2010) 
35. Abbas, N, Nazir, T, Radenović, S: Some periodic point results in generalized metric spaces. Appl. Math. Comput. 217, 4094-4099 (2010)

36. Chugh, R, Kadian, T, Rani, A, Rhoades, BE: Property P in G-metric spaces. Fixed Point Theory Appl. 2010, Article ID $401684(2010)$

37. Abbas, M, Nazir, T, Saadati, R: Common fixed point results for three maps in generalized metric space. Adv. Differ. Equ. 49, 1-20 (2011)

38. Aydi, H, Shatanawi, W, Vetro, C: On generalized weakly G-contraction mapping in G-metric spaces. Comput. Math. Appl. 62, 4222-4229 (2011)

39. Abbas, M, Khan, SH, Nazir, T: Common fixed points of R-weakly commuting maps in generalized metric spaces. Fixed Point Theory Appl. 2011, Article ID 784595 (2011)

40. $\mathrm{Ye}, \mathrm{H}, \mathrm{Gu}, \mathrm{F}$ : Common fixed point theorems for a class of twice power type contraction maps in G-metric spaces. Abstr. Appl. Anal. 2012, Article ID 736214 (2012)

41. Gu, F: Common fixed point theorems for six mappings in generalized metric spaces. Abstr. Appl. Anal. 2012, Article ID $379212(2012)$

42. $\mathrm{Gu}, \mathrm{F}, \mathrm{Ye}, \mathrm{H}$ : Common fixed point theorems of Altman integral type mappings in G-metric spaces. Abstr. Appl. Anal. 2012, Article ID 630457 (2012)

43. Saadati, R, Vaezpour, SM, Vetro, P, Rhoades, BE: Fixed point theorems in generalized partially ordered G-metric spaces. Math. Comput. Model. 52(5-6), 797-810 (2010)

44. Choudhury, BS, Maity, P: Coupled fixed point results in generalized partially ordered G-metric spaces. Math. Comput. Model. 54, 73-79 (2011)

45. Aydi, H, Damjanović, B, Samet, B, Shatanawi, W: Coupled fixed point theorems for nonlinear contractions in partially ordered G-metric spaces. Math. Comput. Model. 54(9-10), 2443-2450 (2011)

46. Shatanawi, W: Some fixed point theorems in ordered G-metric spaces and applications. Abstr. Appl. Anal. 2011, Article ID 126205 (2011). doi:10.1155/2011/126205

47. Luong, NV, Thuan, NX: Coupled fixed point theorems in partially ordered G-metric spaces. Math. Comput. Model. 55(3-4), 1601-1609 (2012)

48. Aydi, H, Postolache, M, Shatanawi, W: Coupled fixed point results for $(\psi, \varphi)$-weakly contractive mappings in ordered G-metric spaces. Comput. Math. Appl. 63(1), 298-309 (2012)

49. Abbas, M, Nazir, T, Radenović, S: Common fixed point of generalized weakly contractive maps in partially ordered G-metric spaces. Appl. Math. Comput. 218(18), 9383-9395 (2012)

50. Cho, YJ, Rhoades, BE, Saadati, R, Samet, B, Shatanawi, W: Nonlinear coupled fixed point theorems in ordered generalized metric spaces with integral type. Fixed Point Theory Appl. 2012, Article ID 8 (2012). doi:10.1186/1687-1812-2012-8

51. Aydi, H, Karapinar, E, Shatanawi, W: Tripled common fixed point results for generalized contractions in ordered generalized metric spaces. Fixed Point Theory Appl. 2012, Article ID 101 (2012). doi:10.1186/1687-1812-2012-101

52. Abbas, M, Sintunavarat, W, Kumam, P: Coupled fixed point of generalized contractive mappings on partially ordered G-metric spaces. Fixed Point Theory Appl. 2012, Article ID 31 (2012). doi:10.1186/1687-1812-2012-31

53. Nashine, HK: Coupled common fixed point results in ordered G-metric spaces. J. Nonlinear Sci. Appl. 1, 1-13 (2012)

54. Mustafa, Z, Aydi, H, Karapmar, E: Mixed $g$-monotone property and quadruple fixed point theorems in partially ordered metric space. Fixed Point Theory Appl. 2012, Article ID 71 (2012). doi:10.1186/1687-1812-2012-71

55. Shatanawi, W, Abbas, M, Aydi, H, Tahat, N: Common coupled coincidence and coupled fixed points in G-metric spaces. Nonlinear Anal. Appl. 2012, Article ID jnaa-00162 (2012). doi:10.5899/2012/jnaa-00162

doi:10.1186/1687-1812-2013-64

Cite this article as: Gu and Zhou: Coupled common fixed point theorems for a pair of commuting mappings in partially ordered G-metric spaces. Fixed Point Theory and Applications 2013 2013:64.

\section{Submit your manuscript to a SpringerOpen ${ }^{\circ}$ journal and benefit from:}

- Convenient online submission

Rigorous peer review

- Immediate publication on acceptance

- Open access: articles freely available online

- High visibility within the field

- Retaining the copyright to your article 